УДК 336.763

\title{
М. М. Сорокина
}

ФГБОУ ВО «Новосибирский государственный университет экономики и управления «НИНХ», Новосибирск, e-mail: m40ina@mail.ru

Н. С. Лис

ФГБОУ ВО «Новосибирский государственный университет экономики и управления «НИНХ», Новосибирск, e-mail: nslis@yandex.ru

\section{УПРАВЛЕНИЕ ПОРТФЕЛЕМ ЦЕННЫХ БУМАГ \\ КОММЕРЧЕСКОГО БАНКА В УСЛОВИЯХ ВОЛАТИЛЬНОСТИ ФОНДОВОГО РЫНКА}

Ключевые слова: фондовый рынок, фондовая биржа, ценные бумаги, банки, портфель ценных бумаг, формирование и реструктуризация портфеля, мониторинг фондового рынка, эмиссия ценных бумаг, акции, облигации.

В текущих условиях вопрос сбалансированного портфеля ценных бумаг привлекает внимание отечественных и зарубежных специалистов. Имеющийся недостаток опыта и практики связан с неравномерным развитием инвестиционной деятельности кредитных организаций на рынке ценных бумаг. В статье дано определение процесса управления банковским портфелем ценных бумаг в условиях волатильности фондового рынка. Обоснована необходимость систематического мониторинга фондового рынка России при формировании и оптимизации банковского портфеля ценных бумаг. Проведено комплексное исследование состояния и тенденций развития отечественного фондового рынка и определено его влияние на инвестиционную деятельность банков. В соответствии с проведённым анализом можно отметить, что инвестиции в ценные бумаги могут быть одним из ведущих направлений банковских операций. В связи с этим портфельным управляющим коммерческих банков стоит обратить внимание на пересмотр структуры активов с целью увеличения удельного веса портфеля ценных бумаг в структуре активов. Благодаря управлению банковским портфелем ценных бумаг, банки получают мощный инструмент наращивания капитала в условиях нахождения оптимальной структуры и объема портфеля зависимости от доходности, уровня ликвидности и риска ценных бумаг.

\section{M. Sorokina}

Novosibirsk State University of Economics and Management «NSUEM», Novosibirsk, e-mail: m40ina@mail.ru

\section{N. S. Lis}

Novosibirsk State University of Economics and Management «NSUEM», Novosibirsk, e-mail: nslis@yandex.ru

\section{PORTFOLIO MANAGEMENT OF A COMMERCIAL BANK AMID STOCK MARKET VOLATILITY}

Keywords: stock market, stock exchange, securities, banks, securities portfolio, portfolio formation and restructuring, stock market monitoring, securities issue, shares, bonds.

In the current environment, the issue of a balanced portfolio of securities attracts the attention of domestic and foreign experts. The existing lack of experience and practice is associated with the uneven development of investment activities of credit institutions in the securities market. The article provides a definition of the process of managing a banking portfolio of securities in the context of stock market volatility. The necessity of systematic monitoring of the Russian stock market in the formation and optimization of the banking securities portfolio has been substantiated. A comprehensive study of the state and development trends of the domestic stock market was carried out and its influence on the investment activities of banks was determined. In accordance with the analysis carried out, it can be noted that investments in securities can be one of the leading areas of banking operations. In this regard, the portfolio manager of commercial banks should pay attention to the revision of the structure of assets in order to increase the share of the securities portfolio in the structure of assets. Thanks to the management of the banking portfolio of securities, banks receive a powerful tool for increasing capital in the context of finding the optimal structure and volume of the portfolio, depending on the profitability, liquidity level and risk of securities. 


\begin{abstract}
Введение
В сложных финансово-экономических условиях банки должны максимально использовать весь имеющийся финансовый инструментарий, одним из мощных составляющих которого является инвестиционная деятельность, а именно - вложения в ценные бумаги. Этот инструмент, к сожалению, отечественными банками используется недостаточно. Особенно актуальным является поиск путей повышения эффективности управления банковским портфелем ценных бумаг в условиях финансово-экономической нестабильности и высоко уровня неопределенности фондового рынка. Анализ последних публикаций выявил, что чрезвычайная актуальность выбранного направления подтверждается многочисленными научными исследованиями инвестиционной деятельности банков. Вопросы по активизации инвестиционной деятельности банков, особенностей процесса управления портфелем ценных бумаг рассмотрены в работах Агешкина Н.А., Балтина В.Э., Выгодчикова И.Ю., Чудиновских М.В., Шапкина А.С. и многих других.

Цель исследования - проанализировать влияние фондового рынка на формирование портфеля ценных бумаг банка; раскрыть сущность процесса формирования портфеля ценных бумаг; обосновать практические рекомендации по управлению банковским портфелем ценных бумаг.
\end{abstract}

\section{Материалы и методы исследования}

Исследование было проведено с использованием следующих теоретических и методологических основ: микроэкономика, макроэкономика, экономическая статистика, теория статистики, которые разрабатывают методы статистического сбора, обработки, анализа и представления статистической информации.

\section{Результаты исследования и их обсуждение}

Сегодня вопрос об оптимальной структуре банковского портфеля ценных бумаг является дискуссионным и выступает объектом внимания отечественных специалистов. Недостаток отечественного опыта и практики формирования и управления банковским портфелем ценных бумаг обусловлен ненадлежащим развитием инвестиционной деятельности банков России на рынке ценных бумаг.

По данным ЦБР, удельный вес портфеля ценных бумаг в совокупных активах банков является незначительным, и в течение 20172019 годов он колебался на уровне 4,5-8,9\%. За 2020 год совокупный объем портфеля ценных бумаг составляет примерно 13,8\% (таблица).

В портфеле ценных бумаг банков на протяжении всего исследуемого периода преобладали бумаги на продажу, около $80 \%$. По срокам погашения наибольший удельный вес занимают ценные бумаги со сроком погашения более 2 лет. В 20182020 годах доля бумаг со сроком погашения более 2 лет значительно снизилась, но осталась на уровне более $50 \%$, в то же время существенно выросла доля краткосрочных ценных бумаг со сроком погашения до 1 года.

Банковский портфель ценных бумаг находится в постоянной динамике, что обусловлено изменениями на фондовом рынке и стремлением банков обеспечить их эффективность путем управления объемами и структурой видов ценных бумаг. Основная задача создания и управления банковским портфелем ценных бумаг является стремление к лучшим условиям инвестирования путем предоставления приобретенной совокупности ценных бумаг таких инвестиционных характеристик, которые нельзя достичь с позиции отдельного вида ценных бумаг, а лишь при условии их комбинации. Управление банковским портфелем ценных бумаг предусматривает оптимизацию состава и структуры совокупности ценных бумаг, учитывая их доходность, ликвидность и уровень риска.

Динамика активов банков, вложений в ценные бумаги, млрд руб.

\begin{tabular}{|l|c|c|c|c|}
\hline \multirow{2}{*}{\multicolumn{1}{|c|}{ Показатели }} & \multicolumn{4}{|c|}{ Года } \\
\cline { 2 - 5 } & $\mathbf{2 0 1 7}$ & $\mathbf{2 0 1 8}$ & $\mathbf{2 0 1 9}$ & $\mathbf{2 0 2 0}$ \\
\hline Активы банка & 926086 & 880302 & 942088 & 1070000 \\
\hline Вложения в ценные бумаги & 40610 & 39335 & 83559 & 87059 \\
\hline \% в общих активах & 4,4 & 4,5 & 8,9 & 13,8 \\
\hline
\end{tabular}


Таким образом, портфель ценных бумаг является тем инструментом инвестиционной деятельности банков, который обеспечивает банку необходимую устойчивость дохода при минимальном риске. Развитию теоретических аспектов управления портфелем ценных бумаг все больше внимания уделяется в последние годы. Отдельные авторы этот процесс рассматривают, как деятельность по формированию и реструктуризации портфеля ценных бумаг при изменении внешних и внутренних условий осуществления финансовых инвестиций [1].

Шевченко А. под управлением портфелем ценных бумаг понимает искусство формировать и распоряжаться совокупностью различных ценных бумаг так, чтобы они сохраняли свою стоимость и приносили ощутимый доход, независимо от специфического риска. Речь идет о создании и применении к совокупности ценных бумаг определенных подходов, методов и технологий, которые позволяют, прежде всего, сохранить инвестированный капитал, достичь максимального дохода и приемлемого уровня риска, ликвидности, а также обеспечить необходимую инвестиционную направленность портфеля [2].

Более в полной мере раскрыта сущность процесса управления портфелем ценных бумаг Шапкиным А.С., под которым он понимает осуществление комплекса мероприятий относительно инвестиционной политики, формирование, анализ, мониторинг портфеля ценных бумаг с целью получения доходов в виде дивидендов и/или участия в эффективном управлении предприятиями (из акций которых сформирован инвестиционный портфель для максимизации экономического эффекта) [6, с. 512].

Следует отметить, что на этапе формирования портфеля речь идет лишь о мониторинге ценных бумаг на фондовом рынке, а уже на этапе структуризации обосновывается необходимость более глубоких исследований инвестиционного климата и конъюнктуры фондового рынка, но, более глубокий и всесторонний анализ необходимо проводить уже на первых этапах формирования портфеля ценных бумаг. В целом абсолютно четко проявляется необходимость систематического отслеживания и накопления информации относительно состояния и тенденций развития фондового рынка, изменения на котором и являются индикатором необходимости просмотра портфеля ценных бумаг.
Аналитические процессы должны проходить параллельно с определением цели и задачи деятельности по ценным бумагам в банке. Владение полной, объективной и актуальной информацией относительно обращения отдельных видов ценных бумаг на фондовом рынке даст возможность планировать состав банковского портфеля ценных бумаг. Кроме того, необходимо подчеркнуть, что информация о состоянии и тенденциях развития фондового рынка необходима, как для обоснованного выбора ценных бумаг в зависимости от их характеристик, так и для планирования типа и структуры портфеля.

Управление банковским портфелем ценных бумаг сопровождается исследованием и анализом ситуации на фондовом рынке, оценкой инвестиционных качеств отдельных видов ценных бумаг по уровню доходности, ликвидности, риску, определению надежности. Итак, до начала планирования деятельности с ценными бумагами банкам целесообразно осуществить комплексное исследование и анализ ситуации, который позволит выявить состояние и оценить тенденции развития фондового рынка, динамику основных показателей отдельных видов ценных бумаг и тому подобное. На протяжении всего цикла деятельности с ценными бумагами необходимо проводить мониторинг ситуации на фондовом рынке для получения информации и разработки решений по реструктуризации портфеля и оптимизации его состава и структуры [4].

Относительно объемов и структуры торгов в 2018 и 2019 годах, ситуация была нестабильной и характеризовалась почти ежемесячными прибавками и падениями объемов торгов. Наиболее существенное падение произошло в феврале и июне в 2019 году, объем торгов тогда составил 274 и 196 млн руб. соответственно. В целом, в 2019 году среднемесячный объем торгов не превышал 2252 млн руб. Общий объем торгов на Московской бирже в 2019 году более чем в шесть раз был меньше по сравнению с 2018 годом. Значимыми для фондового рынка России стали март-апрель 2020 года, объем торгов в марте сначала превысил 5,6 млрд руб., а в апреле вырос до почти 7,5 млрд руб. Но удержать такую позитивную динамику не удалось, в мае объем торгов снизился на $18 \%$ по сравнению с апрелем, в июне еще в два раза, однако объемов торгов удержался на уровне более 3 млрд руб. [2]. 
С началом финансового кризиса темпы прироста объемов эмиссии несколько замедлились. Важным индикатором тенденций на фондовом рынке также является структура торгов на ММВБ-РТС. Анализ данных по развитию торгов на Фондовой бирже ММВБ-РТС акциями и облигациями предприятий и местных органов свидетельствует, что более существенными являются колебания объемов торгов облигациями.

Если в течение ноября-декабря 2018 года, января-мая 2019 года объемы торгов по облигациям снизились до рекордно низкого уровня, объемы торгов акциями в ноябре-декабре 2017 года, январе 2018 года и до ноября 2019 года ежемесячно росли и только в октябре 2020 имели тенденцию к снижению [2].

В соответствии с информацией представленной на Мосбирже по итогам всего 2020 года общий объем торгов на рынках Московской биржи вырос на $18,7 \%$, до 947,2 трлн руб. Позитивную годовую динамику объема торгов продемонстрировали все основные рынки биржи: рынок акций показал рост на 97,3\%, на рынке облигаций наблюдается рост на $8,5 \%$.

Итак, во время мониторинга фондового рынка для принятия решений об оптимизации банковского портфеля ценных бумаг важным направлением является: анализ динамики фондовых индексов; анализ объемов торгов в целом и по отдельным видам ценных бумаг; отслеживание изменений индексной корзины ММВБ-РТС по цене по- следней сделки; оценка изменений в структуре эмиссии ценных бумаг.

\section{Заключение}

Среди активных операций банков вложение в ценные бумаги по значимости и размерами находится на втором месте после кредитования. В современных условиях специалисты банков пытаются доказать необходимость пересмотра структуры активов с целью увеличения удельного веса портфеля ценных бумаг в структуре активов.

В России в банковском секторе не используется потенциал такого мощного инструмента, как банковский портфель ценных бумаг. Благодаря управлению банковским портфелем ценных бумаг, которое предусматривает сначала его формирование, а затем и реструктуризацию в зависимости от влияния внешних и внутренних факторов, банки получают мощный инструмент наращивания капитала в условиях нахождения оптимальной структуры и объема портфеля по видам ценных бумаг в зависимости от их доходности, уровня ликвидности и риска. Прогнозирование дальнейшего развития фондового рынка является сложным, и любой прогноз будет иметь невысокий уровень вероятности. При таких условиях своевременное отслеживание и реагирование на изменения рынка ценных бумаг России банками путем управления банковским портфелем ценных бумаг становится обязательным условием эффективности деятельности банков с ценными бумагами.

\section{Библиографический список}

1 Агешкина Н.А., Кайль А.Н. Комментарий к Федеральному закону от 5 марта 1999 г. N $46-Ф 3$ «О защите прав и законных интересов инвесторов на рынке ценных бумаг». Саратов: Ай Пи Эр Медиа, 2019. $84 \mathrm{c}$.

2 Балтин В.Э., Булатова Ю.И. Рынок ценных бумаг: практикум для СПО. Саратов: Профобразование, 2020. 139 c.

3 Выгодчикова И.Ю. Методы анализа рынка ценных бумаг: учебное пособие. Саратов: Ай Пи Ар Медиа, 2019. 200 с.

4 Курс по рынку ценных бумаг. Новосибирск: Сибирское университетское издательство «Норматика», 2016. $117 \mathrm{c}$.

5 Чудиновских М.В. Правовое регулирование рынка ценных бумаг: учебник. Саратов: Ай Пи Эр Медиа, 2018. $191 \mathrm{c.}$

6 Шапкин А.С., Шапкин В.А. Управление портфелем инвестиций ценных бумаг. М.: Дашков и К, 2018. $512 \mathrm{c}$. 